\title{
Role Playing in Engineering Education
}

\author{
Michael Bartz and Russell J. Deaton \\ The University of Memphis
}

\begin{abstract}
Role playing allows engineering students to participate in many activities in which professional engineers engage. Examples include product research and development, job hunting, identification and evaluation of vendors, business present at ions and meetings, team projects, reports, and management. At The University of Memphis, an inter-course project used role playing to introduce students to these "soft" engineering skills. The inter-course project involved a senior elective in Discrete-Time Signal Processing (DSP), and a junior electronics course. Students within the courses were broken into teams or "companies" with the engineering goal of developing a signal processing system. Students prepared resumes and interviewed for positions with each "company." DSP teams developed system-level specifications, and the electronics teams developed digital-to-analog converters to meet the specifications. The DSP teams had to evaluate the electronic teams' products, as well as real vendors', on price and performance for incorporation in their systems. Different DSP teams had to design their systems to meet specific performance and price criteria for different applications. The electronics teams did sales presentations to the DSP teams, and designed their products to meet the DSP team specifications. The student teams were rated competitively based upon the demonstration of professional skills, such as oral presentation and written specifications, and product performance and price.
\end{abstract}

\section{Introduction}

While recognizing the need for instruction and practice in the formal techniques of electrical engineering, students often express a need for skills and experiences that are closer to what they will experience as practicing, professional engineers. Some of the skills are written and oral report preparation, working in groups, managing other workers, realistic cost estimates and budget preparation, interfacing with other engineers and vendors, and resume and interviewing skills. An example of a real-world engineering situation is a problem or design task that is incompletely specified, and situations in which unforeseen difficulties and problems arise. Therefore, to address this type of engineering knowledge, an inter-course project between two junior and senior electrical engineering courses combines the traditional lecture and practice on "hard" techniques, and practice on "soft" skills, such as those mentioned above.

\section{Inter-course and Intra-course Project Descriptions}

In a junior electronics class and senior discrete-time signal processing (DSP) class, a inter-course project was designed and implemented to give the students a realistic engineering experience and practice with professional skills. The students in each course were divided into teams that simulated engineering units of a larger company. The DSP "companies" designed a recording and playback system for either 
a commercial or military application. The electronics companies designed, built, and manufactured a . digital-to-analog (D/A ) device as specified by the DSP teams.

- The composition of the "teams" within each course varied, but they represented typical functions in an engineering team including project management, sales, design, quality control, and manufacturing. The professors accepted resumes, including a cover letter, and interviewed students for various positions within the teams. Following the interviews, the instructors formed the companies.

The instructors promoted inter-course interaction via informal methods and through two formal all-teams meetings. The all-teams meetings were chaired by the instructors and used as information dissemination and exchange between the companies. The specific details of each courses' companies are described below.

\section{Electronics Project}

As stated above, the students in the electronics course divided into companies with a design goal of producing a D/A converter that would meet their customers (the DSP teams) specifications. The engineering teams were allowed latitude in their formal composition, but all teams were required to have one project manager. Other identified functional areas included the following:

1. Design engineer: designs and constructs the laboratory prototype.

2. Quality control engineer: specifies the manufacturing quality plan

3. Manufacturing engineer: specifies the manufacturing process including costs

4. Sales engineer: develops technical sales literature and price information

Some teams assigned one individual to each functioned area, whereas other teams used a shared responsibility approach. Exact configurations of the teams was the purview of the project manager, who was directly responsible to the instructor.

The electronics course is a four-semester hour course with an integrated laboratory. The construction and design of the D/A was integrated seamlessly into the laboratory experience. In a normal laboratory section, students construct three design projects in addition to eight instructional demonstrations. The D/A project replaced the design projects and one regular demonstration. The remaining demonstrations and experiments were re-oriented to serve as instructional modules for the D/A project. For example, the differential amplifier design experiment provides a good start for several D/A designs. For pedagogical purposes, the students were limited to using transistors, op-amps, and small-scale integrated circuits in the construction of the electronics portion of the D/A. In addition to normal laboratory meetings, the laboratory was also run in an "open" mode, i.e., students were allowed to use the laboratory whenever it was available.

The professional activities in which the students engaged included weekly reports, team meetings, scheduling, and budgeting. Including the weekly reports, each engineer was required to produce a final deliverable that represented their work over the course of the project. For example, the design engineers produced a laboratory prototype and a final design specification, and the quality control engineer produced a testing and feasibility plan along with a predictive analysis per piece quality and reliability. In addition, each engineer was responsible for an informed evaluation of the project manager's performance, or in the project manager's case, each subordinate engineer's performance. The individual grades were 
a combination of their particular final deliverable, a common team score based upon the final product, . their weekly reports, and" the intra-team evaluations.

\section{DSP Project}

In the DSP class, the students were divided into teams that simulated engineering companies. The task of each company was to design a recording and playback system for either a commercial or military application. The commercial product was a toy to record and playback voices and music, and the military product was a sonar system for the detection of both man-made and natural signals. The system incorporated material from the formal coursework. Specifically, the teams had design a sampling scheme, analog to digital (A/D) and D/A converters, and anti-aliasing filters.

Each team consisted of a project manager, four design engineers, and one or two product engineers. Their tasks were:

1. Project Manager: Responsible for overall project, assign tasks to other team members, evaluate performance, make decisions, and interact with the CEO, Dr. Deaton.

2. Design Engineer (2): D/A Design.

3. Design Engineer (2): A/D Design.

4. Product Engineer: Interact with electronics teams. Publish specifications, evaluate designs, negotiate pricing, business management.

The plan was to have the teams evaluate the electronics classes D/A designs, negotiate a price, put out bid, and sign a contract for this component of the designs. Because the electronics classes were late in completing their designs, this restriction was relaxed, and all teams were allowed to identify and price components for their designs from commercial vendors. The prices for the commercial products were constrained to be lower than the military application. The teams conducted library research not only for their design components, but also for the bandwidth and characteristics of the signals for their specific applications.

For the DSP teams, the instructor conducted interviews for the project manager or product engineer positions. The project managers were directly responsible for all aspects of the project. They also interacted with the professor and provided him with periodic progress reports, both formal and informal. The product engineers also interacted with the professor, as he served not only as CEO of all companies, but also as the companies' customer. The product engineers negotiated prices with the customer and with the electronics teams. A final report and presentation were due at the end of the project. Each team received a common grade based on the technical merit of their design. Extra credit points were assigned based on each teams profit, quality of presentation, and organizational efficiency.

\section{Project Results}

\section{Electronics Project}

The D/A design project was integrated in the traditional laboratory and was purposefully intended as a open-ended, unconstrained problem. One of the primary pedagogical goals was the development of resource allocation and review by the student engineers. This project had very little formal or informal treatment in currently used textbooks and required students to go outside normal channels of information retrieval. For example, the design engineers performed literature and bibliographic reviews of both the 


\begin{tabular}{|c|c|c|}
\hline \hline Team & Application & Cost \\
\hline A & Military & $\$ 25.50$ \\
\hline B & Military & $\$ 2295.00$ \\
\hline C & Military & $\$ 2000.00$ \\
\hline D & Commercial & $\$ 41.19$ \\
\hline E & Commercial & $\$ 30.98$ \\
\hline F & Commercial & $\$ 16.61$ \\
\hline G & Commercial & $\$ 105.45$ \\
\hline
\end{tabular}

Table 1: Final products costs for DSP teams.

academic and professional literature. They conducted inter-library loan retrievals and reviewed product application notes. They integrated their acquired knowledge into designs that were tested using computerassisted tools (SPICE) along with bench-level testing. Quality control engineers reviewed literature on testing 'methodologies and reliability estimation.

The class was divided into three teams. Two teams successfully developed, tested, and constructed a laboratory prototype of a working D/A. Both working D/A's used a differential amplifier current steering design based upon designs from available literature. The completed prototypes had eight-bit resolution up to $100 \mathrm{kHz}$. All the teams developed sales presentations and quality control documents. The sales presentations afforded examples of the creative talents of the student engineers.

\section{DSP Project}

The in-class presentations and project reports were designed not only to provide the technical details of the project, but also as a sales document for the teams' product. Therefore, an emphasis was placed on professionalism during the presentations and in the reports. The design goals were purposefully vague, and each team, through discussion with the customer, had to define the limits and goals of their project. Teams also had to identify components and design parameters to fit their customer's needs. Necessarily, the military application had more stringent requirements than the commercial application, and the customer for the military application was willing to pay for performance, while the commercial customer's main interest was low cost. Each team had to produce a cost estimate per component with a reasonable profit margin included. The extra credit points were partially based on the reasonableness of this cost estimate. Costs for all teams are shown in Table 1.

All the teams completed the project, and the professor was impressed with the designs and the amount of effort by the teams. In addition, the students seemed to have fun with the project, and during its course, were excited about it. In addition, one team had a member take leave for a pregnancy, and other members of the team had to take up her responsibilities, which added to the realism of the simulation.

The project managers were asked to summarize the project for the professor. A particularly insightful example follows.

Overall, the design project was a success in that it taught us to work together as a group as it would in the real world. From the beginning with the process of going into an interview after sending out a resume, the entire project helped our group realize that a great many ' 
- more -things.. go into engineering than knowing Ohm's law. The design problem itself posed an $(s i c)$ new and interesting question. By being given such a broad, general topic, we had to rely on questions and our own creativity to come forth with a design. It was tremendous practice for when we venture out into the work place...On a personal note as project manager, I found that your major trouble is at the beginning and the end. In the beginning, you must determine the problem, set goals, and assign duties. In the middle of the project, when you have good people, you can let them do their work with minimum supervision. However, the end of the project requires the most work. You must collect all the information that your group has obtained and be able to present it in a logical and clear manner.

\section{Project Student Evaluations}

The instructors conducted surveys of the students before and after the project. Summarizing the results, one-third of the students in the class had never prepared a resume or been through a formal interview. Most students had done projects in other classes, but not one that engaged the students to the depth that this one did. In general, they liked this project, thought it was more "real-world," and learned. something from it. They also like the laboratory experience.

Free form comments on the project were also collected and are summarized. The students liked the group and team experience, the interview and resume writing process, the realistic aspects of the project, the challenge of "new" or interesting material, and the feeling of being a real engineer. They did not like the inter-course interaction, the intentional vagueness of the design goals, and the lack of participation by some team members. The open-ended nature of the project also led some to consider the project as "too time-consuming" and disorganized.

\section{Project Summary}

The one pedagogical improvement for future projects is the formal development of the managerial and professional skills of the student engineers, in particular, the project manager. The students were unaccustomed to formal organizations in the context of an academic course and were sometimes uncomfortable with imposed lines of authority. In future projects, one or two short seminars on professional skills will be added to augment technical sessions.

In general, the projects were a success. The students like the projects and were excited about it, both of which helped them learn and be interested in the material. Those who fully participated received some real-world experiences and skills. As is always the case, some students shirked their responsibilities, and viewed the project as a way to get a grade without doing any work. This was the number one complaint about the project, and is a problem with this type of work. The number of non-performers, however, was small, and most students got a positive benefit from the experience.

Michael J. Bartz is an Assistant Professor in the Department of Electrical Engineering at The University of Memphis. He received a B.S.E.E. and M.S. from The University of Memphis in 1983 and 1988, respectively, and a Ph.D. in 1992 from the Georgia Institute of Technology.

Russell Deaton is an Assistant Professor in the Department of Electrical Engineering at The University of Memphis. He received a B.S.E.E. from The University of Memphis in 1984, and M.S. in 1988 and Ph.D. in 1992 from Duke University. 